\title{
CPS Function for System Failure
}

\author{
S. Hemalatha, A. P. Shanthana Roja, S. Suruthi, S. Srija
}

\begin{abstract}
A group of interacting or interrelated entities that forms a unified whole is known as a System. A system is portrayed by its spatial and temporal boundaries surrounded and influenced by its environment and it is also described by structure, purposes and expressed in its functioning. There are multiple types of problems, they are BSOD(Blue Screen Of Death), Missing of DLL Files, Computer Restarting Multiple Times, Overheating, Slow internet, Strange Noise, Slow computer, Failure of Peripheral devices, Downloading takes forever, Computer Freezes, App command not working, Jumbled computer screen. This problem may cause severe impact on the system, to avoid those impact it is mandatory to prevent the system from those problems before that occurs. There comes the major role of Cyber Physical System (CPS), which notifies the system about the problem before it occurs. CPS may be defined as combination of physics and cyber components, potentially networked and tightly interconnected with each other. Here, the term physics refers to the plant/process/system and the term cyber refers to the components/software/code. In the interconnection of the physics and cyber, two interfaces are used, one interface is used when the physic is connected to cyber and the other is used in vice versa. The first interface contains network and a convertor, which converts analog signals to digital, and the second interface consist of network and a convertor which converts digital signals to analog. The various application of CPS includes tracking and analysing $\mathrm{CO} 2$ emission, detect traffic accidents, insurance telematics and provide situational awareness services to first responders, measure traffic, monitor cardiac patients, etc. Our main aim is to deal with the usage of the CPS in various system failures. This paper gives a detailed description about the function of CPS in various system failures.
\end{abstract}

Keywords: CPS, Failure of devices, System, Rectification of problems.

\section{INTRODUCTION}

A Computer is a machine that has been designed to perform sequence of arithmetic or logical operation according to the instructions given, automatically through computer programming. A Computer is an electronic device that is designed for storing data and processing them, that is in binary form according to the instructions specified in the program [1]. The recent modern computers are designed with the ability to perform generalized set of operations called program.

Revised Manuscript Received on October 30, 2019.

* Correspondence Author

S. Hemalatha*, Working as a Professor in Computer Science and Engineering in Panimalar Institute of Technology, Chennai, India.

A. P. Shanthana Roja, Computer Science and Engineering in Panimalar Institute of Technology, Chennai, India.

S. Suruthi, Computer Science and Engineering in Panimalar Institute of Technology, Chennai, India.

S. Srija, Computer Science and Engineering in Panimalar Institute of Technology, Chennai, India.

(C) The Authors. Published by Blue Eyes Intelligence Engineering and Sciences Publication (BEIESP). This is an open access article under the CC BY-NC-ND license (http://creativecommons.org/licenses/by-nc-nd/4.0/)
The four major functions of computer is that to collect data (or to allow the users to input data), to process the data manipulate, calculate and to organize them), output the data (display the result or the final information to the users according to the need), to store the data and information for later uses [2]. Charles Babbage is the person who came with the concept of designing a computer; he is an English mechanical engineer, a mathematician, philosopher, Inventor and polymath. He was born on 26 December 1791 Southwark London and died at 18 October 1871 Marylebone, London. He preceded his scientific career at Trinity College,Cambridge [3]. The four major parts of the computer are the ALU, the control unit, the memory, the input and output devices. The Evolution of Computers has 5 generations, first generation is

between 1940 to 1956 i.e., Vacuum Tubes, these early vacuum tubes as circuitry and magnetic drums of memory, second generation is between 1956 to 1963 i.e., Transistors, third generation of computer is between 1964 to 1971 i.e., Integrated circuits, fourth generation of computer is between 1972 to 2010 i.e., Microprocessors and the fifth generation is from 2010 to present day i.e., Artificial intelligence [4].

\section{VARIOUS FAILURES AND SOLUTIONS:}

\section{A. Blue Screen Of Death (Bsod)}

The BSOD is also known as STOP ERROR. When a fatal system error occurs, there will be an error screen displayed on the windows computer system and this is called as blue screen of death. This condition occurs when the operating system reaches a state where it no longer operates safely. The BSOD can be symptom of hardware problem [5].

SOLUTION:

- Check whether you have just installed any new program, update driver, install a windows update, etc., If so, the BSOD may due to the changes that you made in your system. So just undo the change you made and test again for the stop error.

- Make sure if there is enough free space left on the windows drive.

- Some viruses may also cause BSOD, so scan your system for virus.

\section{B. Missing Of .Dll Files}

DLL stands for Dynamic Link Library. It contains a set of code and data for carrying out particular activity in windows. It occurs due to faulty hardware that can corrupt files when they are in use. It may also occur when the newly installed file replace it with the up-to-date DLL files [6].

\section{Published By:}

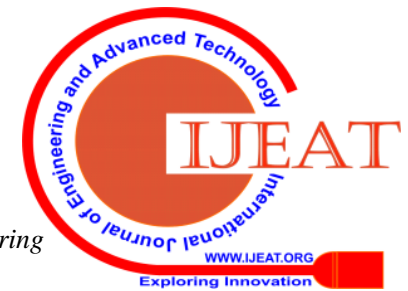




\section{CPS Function for System Failure}

\section{SOLUTION:}

- If the DLL is installed with an app, instead of installing from a separate package, the better reinstall the app.

- You can also copy a DLL file from your installation media.

\section{Computer Restarting Multiple Times}

Hardware failure can cause the computer to reboot. It may due to the problem occur in the RAM, hard drive, power supply, graphics card or external devices [7].

SOLUTION:

- You can disable the automatic restart.

- This problem can be solved by updating the drivers.

- The computer should be scanned for viruses.

\section{Overheating}

When a computer generates more heat than it is designed to handle, then it is called as overheating. In this situation the system will automatically turned off to avoid permanent damage, especially to prevent damage to the processor. It may be due to poor ventilation, underperforming drive, dust, inadequate power supply, etc [8].

SOLUTION:

- Moving the computer to a place where there is good ventilation

- Ensure that you have a good power supply

- Replace defective hardware

\section{E. Slow Internet}

Broadband router configuration errors, wireless interface, or any of several other technical problems adversely affect the speed and stability of the internet connection [9].

SOLUTION:

- Check the router setting.

- Avoid signal interference.

- Beware of worms and malware.

- Stop background programs.

\section{F. Strange Noise}

The computer hard drive is mainly responsible for the strange noise. It is normal to hear some noise from the hard drive, but some noise that you should not expect to hear are repetitive clicking, very noticeable humming, knocking, or any hard thump [10].

SOLUTION:

- Use a blower to make it dust free

- Remove some start up and unwanted programs

- Check the power setting

- Apply some thermal paste on the CPU

\section{G. Computer Is Slow}

It may due to any malware or too many start-ups or may be due to building up of many files. If the problem is because of hardware then it could be hard drive fragmented or due to low memory RAM or HD storage [11].

SOLUTION:

- Uninstall unused programs and delete temporary files.

- Install a solid state drive.
- Run a disk cleanup.

- Run a disk defragment.

\section{H. Failure Of Peripheral Devices}

This includes failure of keyboard, mouse, printer and many other peripheral devices. It may be due to driver issues, computer port problems or peripheral component problems [12].

SOLUTIONS:

- There may be any damages in the USB cable or hub.

- There may be problem with wireless keyboard or mouse, so try to check for its error.

\section{Downloads Take Forever}

This problem may be due to unstable or slow internet connection, or may be due to downloading too many files at a time or because of computer viruses [13].

\section{SOLUTION:}

- Check for the network connection

- Download the files one by one

- Stop running software or files while downloading

- Scan for computer viruses

\section{J. Computer Freezes}

The freezing of computer may occur during both normal mode and safe mode. It also may be an indication of a problem in computer's hardware, overheating of CPU, bad memory or a failing power supply [14].

SOLUTION:

- Avoid overheating of computer

- check for the stable power supply

- Check for the hardware problems.

\section{K. App Command Not Working}

It is a most common problem in Windows and Mac OS. It may be due to software or hardware conflict. Lack of system resources, a bug or a software or driver error can cause the app to stop responding [15].

SOLUTION:

Some of the solutions may include:

- Restarting of computer

- Scan for viruses

- Update the drivers

- Troubleshoot your computer

\section{Jumbled Computer Screen}

This may be due to the problem in display settings, or there may be a problem in the graphic card of the device driver and this prevent the computer from properly displaying a video [16].

SOLUTION:

- Check for the cable connection

- Reset your computer

- Select the screen resolution

Published By: 


\section{CYBER PHYSICAL SYSTEM}

The cyber physical system (CPS) is a smart system that is controlled by computer based algorithm, it is closely related with the internet of things (IOT), and they have almost same architecture. The CPS is integrated with the computer and its users. In CPS the software and physical components are deeply intertwined with each other. Some of the examples of CPS are smart grid, autonomous automobile systems, medical monitoring, process control systems, and automatic pilot avionics [17]. The term cyber physical system was coined around 2006 by Helen Gill at the national Science Foundation in the United States. The CPS focuses on the fundamental intellectual problem of conjoining the engineering traditions of the cyber and physical world. The researchers show their interest in this domain, including theoretical foundations, design and implementation, real world applications, and education. The advancements of CPS includes energy management, data transmission and management, network security, model based design, control technique, system resource allocation and applications [18].

\section{ARCHITECTURE DIAGRAM}

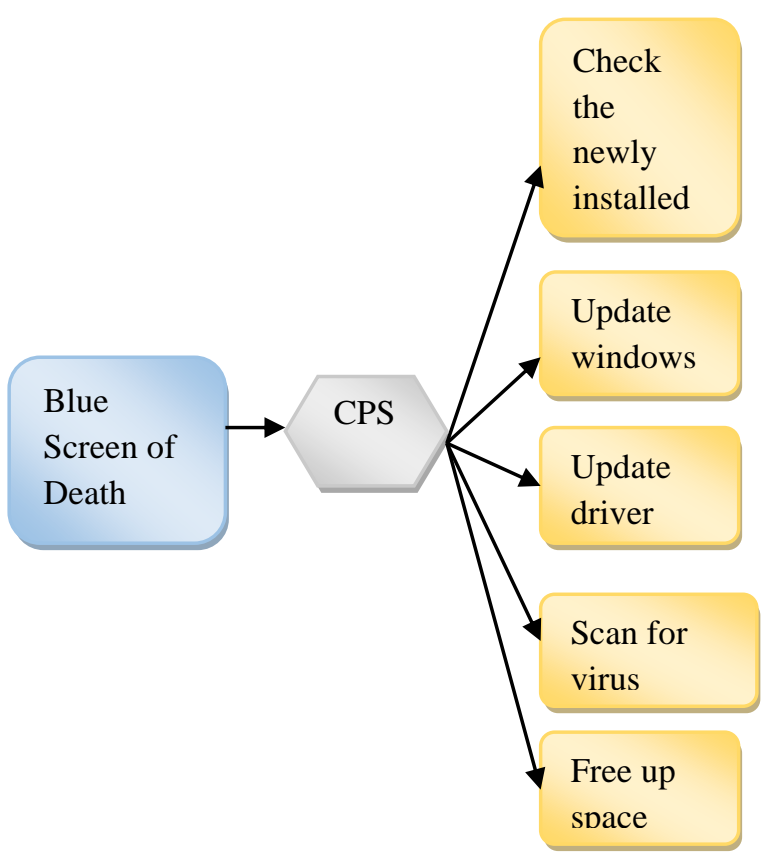

Fig.1.(CPS action for BSOD)

When the BSOD occurs, the CPS will notify to do some activities like checking the newly installed program, updating the windows, updating the driver, scanning for virus and to free up the space. The cause of the problem is found, and the corresponding OS is called for taking action.

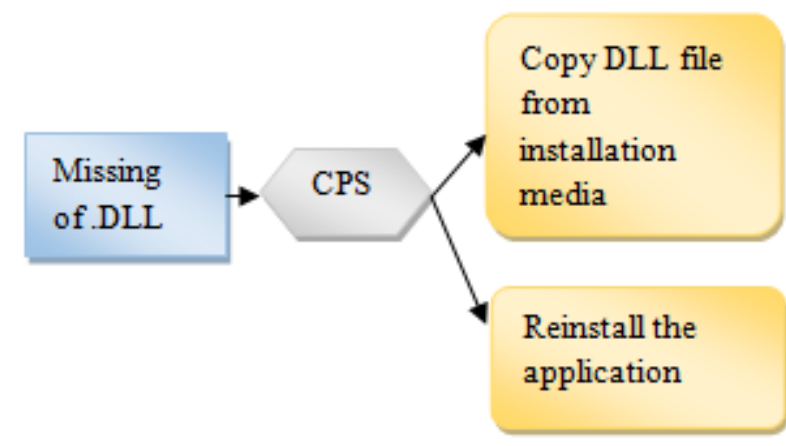

Fig.2.(CPS action for missing of .DLL files)

When there is a missing of .DLL files, the CPS will notify the system to do some activities like reinstalling the application, copying DLL files from the installation media, etc., after finding the cause of the problem, the respective OS is called to take some action.

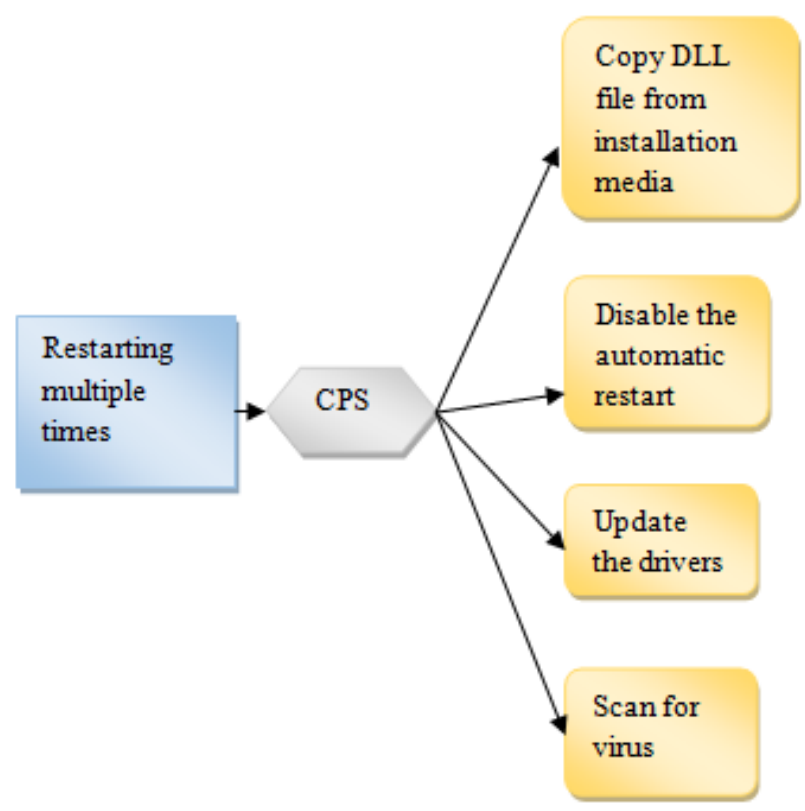

Fig.3. (CPS action for multiple restarting of system) When the system restarts multiple times, the CPS notify to perform some activities like checking the power supply, disabling the automatic restart option, updating the drivers and scanning for virus. After the cause of the problem is found the respective OS is called to take action. 
CPS Function for System Failure

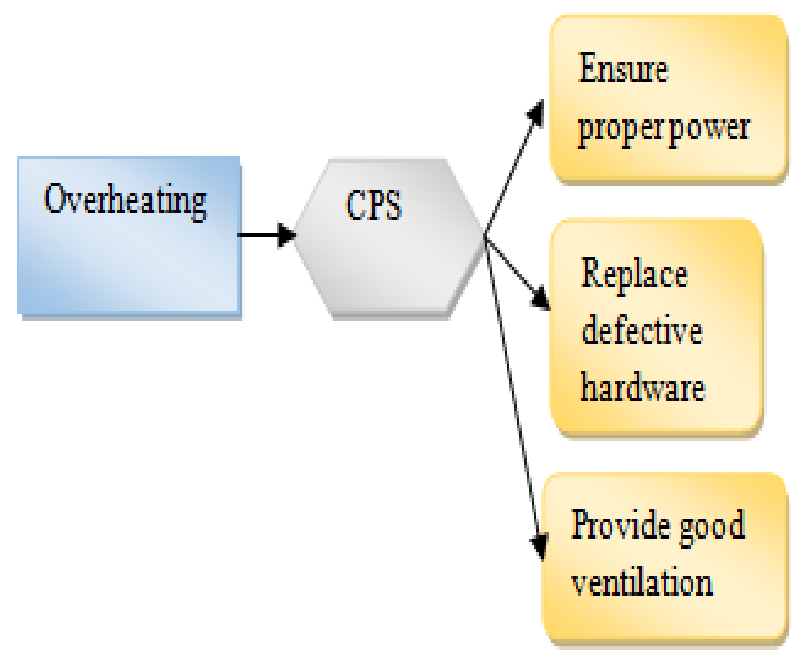

Fig.4: (CPS action for overheating)

When the overheating of system occurs, the CPS will notify to ensure the proper power supply, replacing of defective hardware and to provide good ventilation. Then after finding the cause of the problem the corresponding OS is called and the respective action is taken.

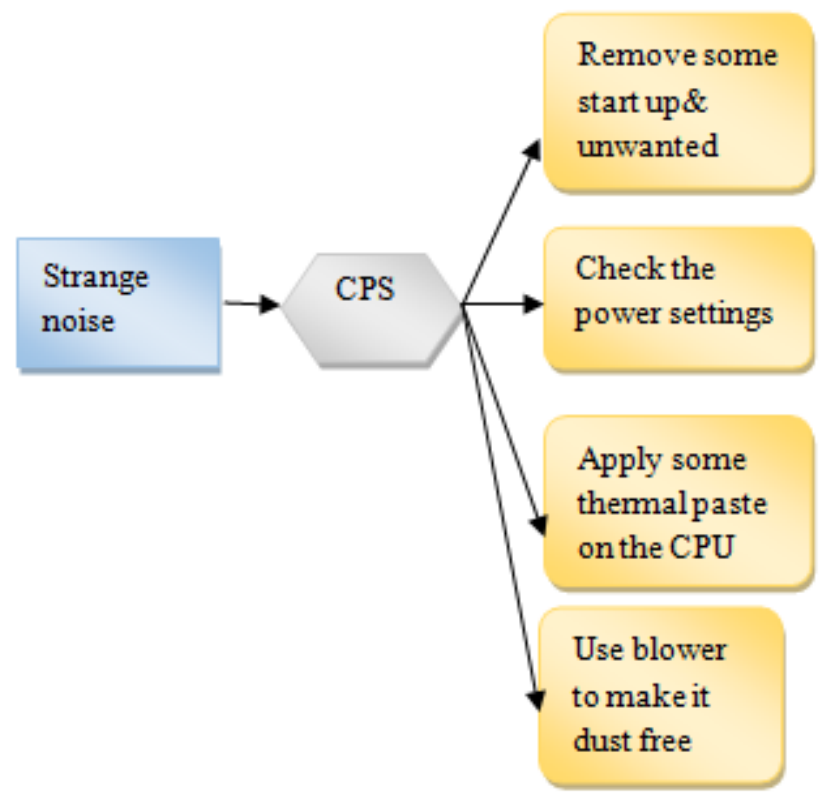

Fig.5 :( CPS action for slow internet)

When there is a problem in the internet connection, the CPS notify to do the following activities: Checking router setting, avoiding signal interference, scanning for worms and malwares and to stop the running of background programs, then the OS corresponds to the problem is called and the respective action is performed.

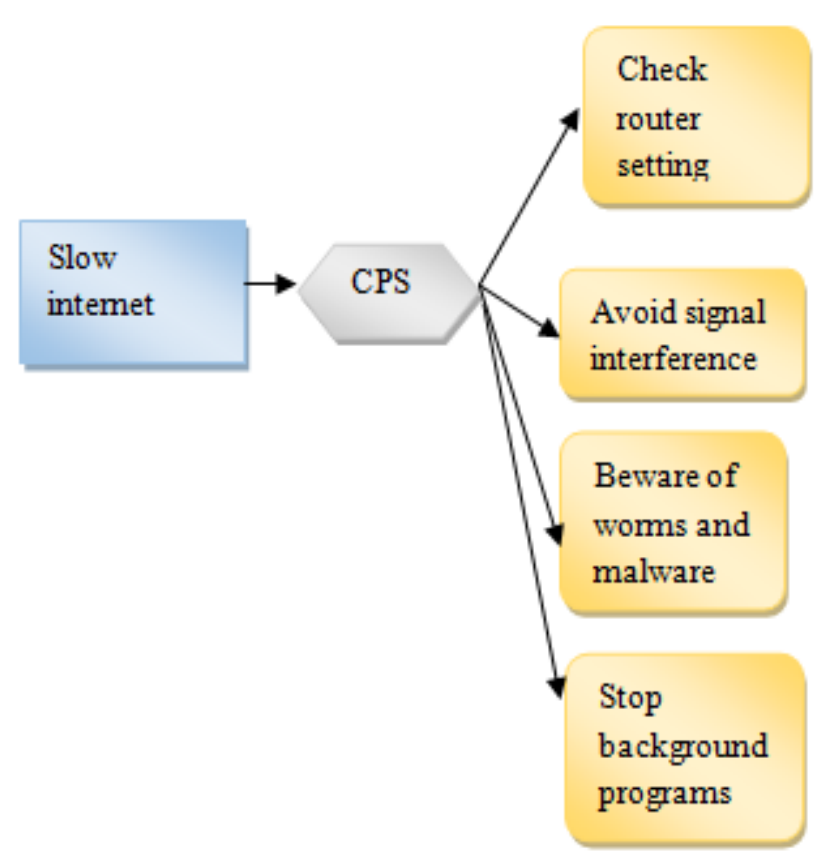

Fig.6: (CPS action for strange noise)

When there is some strange noise in the system, the CPS will notify to use blower to make it dust free, remove some start up and unwanted programs, checking the power setting and to apply some thermal paste on CPU. The corresponding OS is then called to take respective actions.

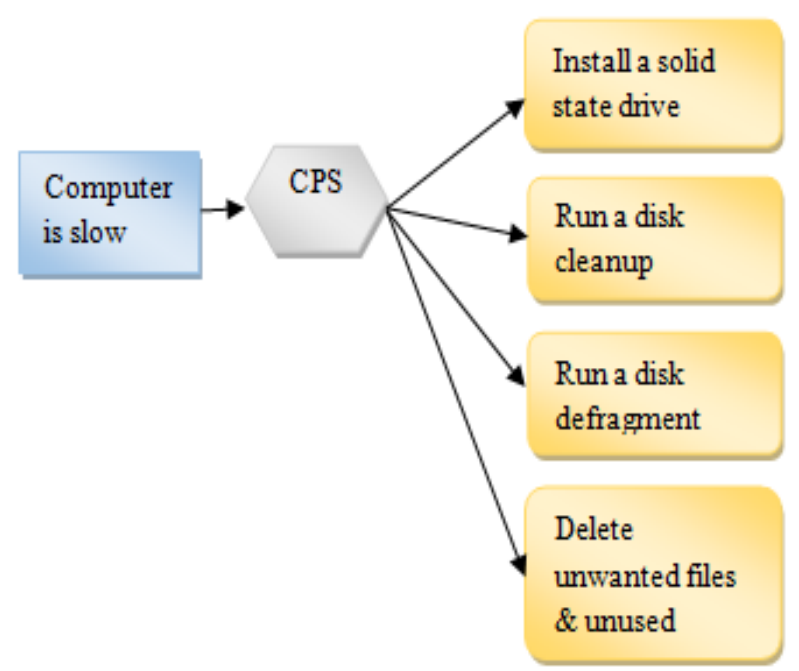

Fig.7: (CPS action for slow working of computer)

When there is a slow working of computer, the CPS will notify to delete the unwanted and unused files, install a solid state drive, run a disk clean up and to run a disk defragment. After finding the correct cause of the problem by checking all the possibilities, the respective OS is called to take the particular action. 


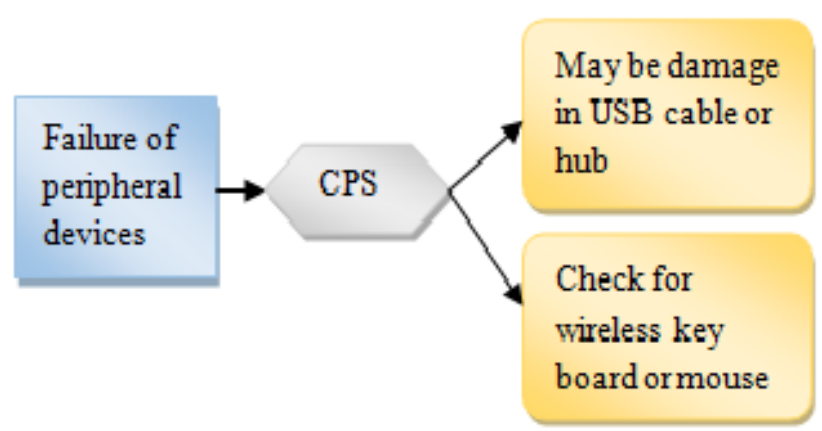

Fig.8: (CPS action for failure of peripheral device)

When the peripheral device fails, the CPS will notify to check whether there is any damage in the USB cable or hub and to check for the connection of wireless keyboard and mouse, then the respective action is taken by the corresponding OS.

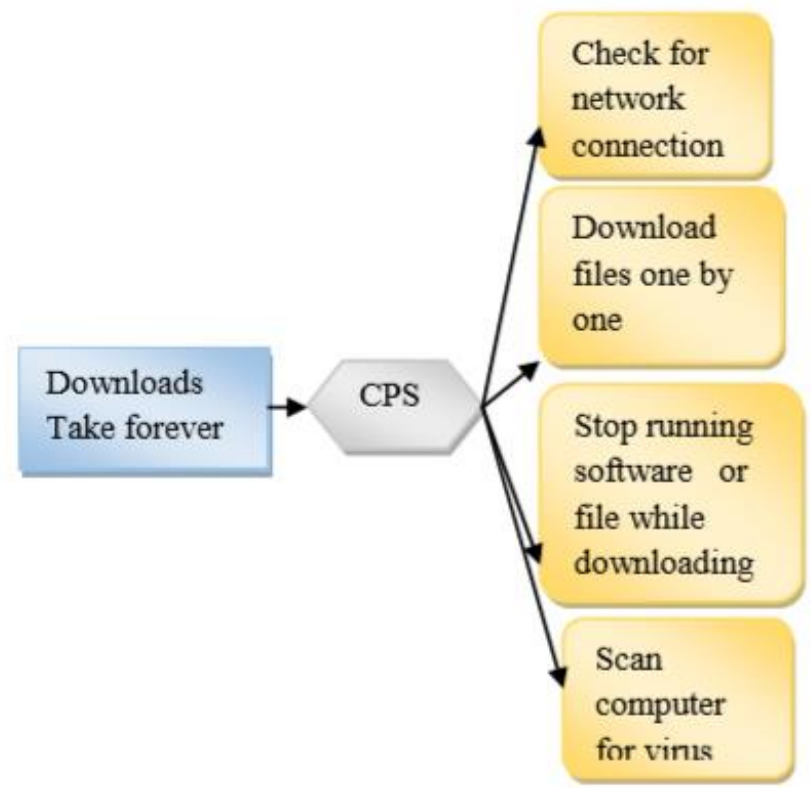

Fig.9 :( CPS action for very slow downloading process)

When the downloading of files or some software takes a long time, then the CPS notify to do some activities like check for the network connection, downloading the files one by one, to stop running software or files while downloading, to scan computer for virus, etc. Then the corresponding OS is called to perform the respective action.

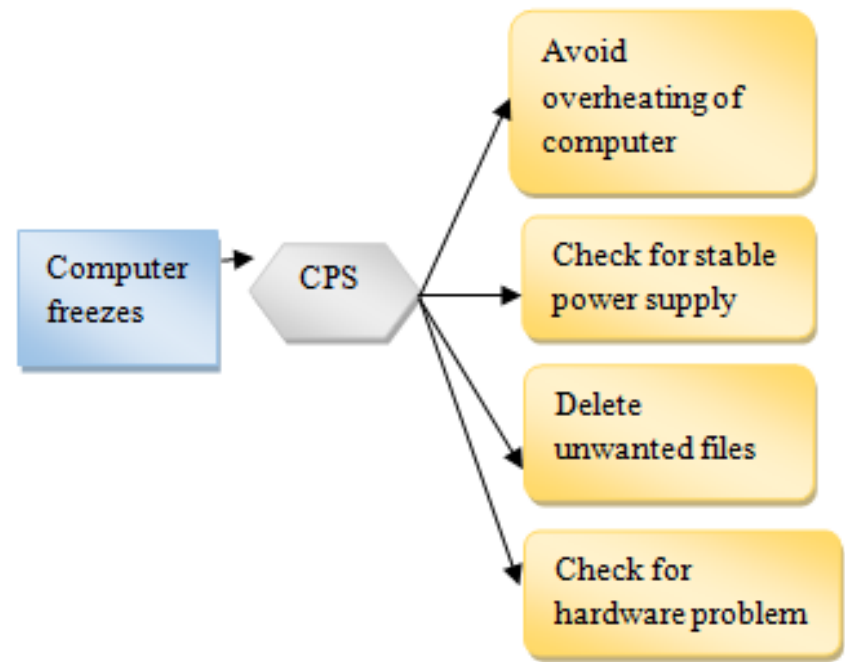

Fig.10 :( CPS action for freezing of computer)

When there is an occurrence of a problem called computer Freezes, then the CPS notify to avoid overheating of computer, to check for stable power supply, to delete unwanted files and to check for any hardware problem that might occur. Then the corresponding OS will be called to take the necessary action.

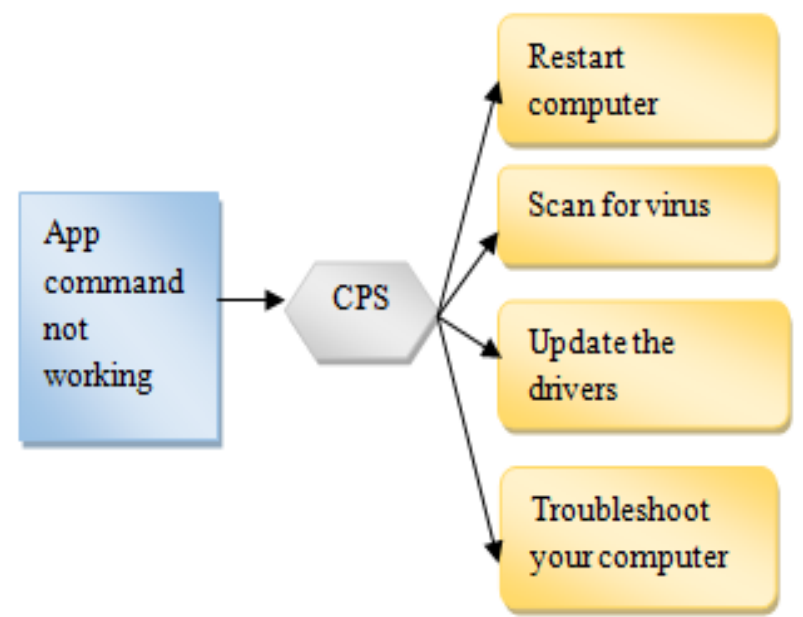

Fig.11: (CPS action for App command not working)

When there is a problem in working of any application in the system, then the CPS will notify to do some activities like restating of computer, scanning for virus, updating the drivers and troubleshooting of the computer. Then the corresponding OS is called to take the necessary action. 
CPS Function for System Failure

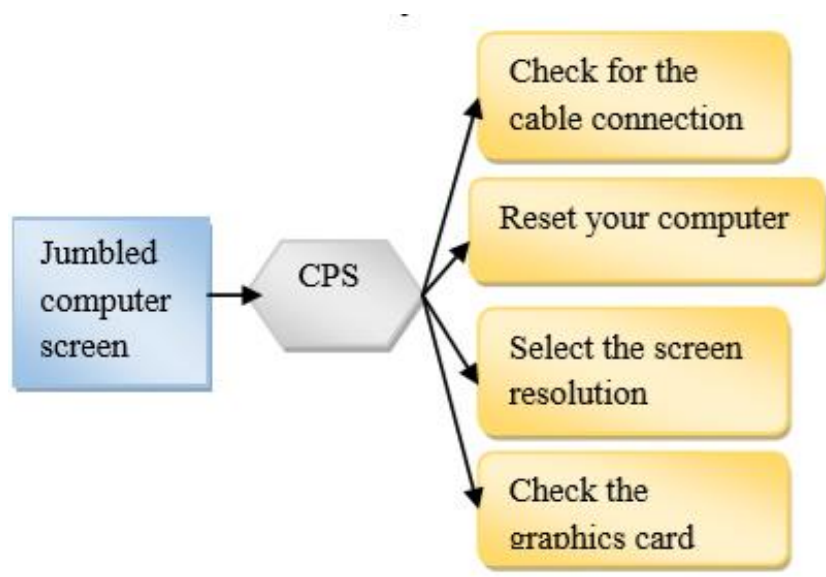

Fig.12: (CPS action for jumbled computer screen)

When there is a jumbled computer screen, the CPS will notify to check the Cable connection, to reset the computer, to select the screen resolution and to check the graphic card. Then the corresponding OS is called and the necessary actions are taken.

\section{RESULT AND DISCUSSION}

If we implement this CPS, then we can prevent the system from data loss, component damage and some other major problem or a big trouble. Preventing the system from various problems will reduce the maintenance cost of the system, increases speed and performance. If we further develop this project, in future it may also be implemented in various machines used in industries. This will make the human work simpler.

Table-I: Advantages of using CPS to prevent the above mentioned failures

\begin{tabular}{|c|c|c|c|c|c|}
\hline \multirow[b]{2}{*}{$\begin{array}{l}\text { SI. } \\
\mathrm{N} \\
\mathrm{O}\end{array}$} & \multirow[b]{2}{*}{$\begin{array}{l}\text { Types of } \\
\text { the } \\
\text { failures }\end{array}$} & \multicolumn{4}{|c|}{ Advantages of using CPS } \\
\hline & & 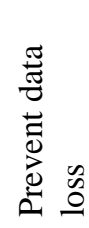 & 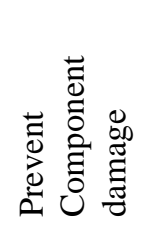 & 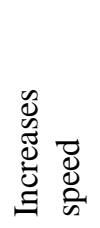 & 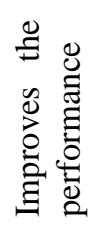 \\
\hline 1 & $\begin{array}{l}\text { Blue } \\
\text { screen of } \\
\text { death }\end{array}$ & $\checkmark$ & & & $\checkmark$ \\
\hline 2 & $\begin{array}{l}\text { Missing } \\
\text { of .DLL }\end{array}$ & $\checkmark$ & & & $\checkmark$ \\
\hline 3 & $\begin{array}{l}\text { Restartin } \\
\text { g } \\
\text { multiple } \\
\text { times }\end{array}$ & $\checkmark$ & & & $\checkmark$ \\
\hline 4 & $\begin{array}{l}\text { Overheat } \\
\text { ing }\end{array}$ & & $\checkmark$ & & $\checkmark$ \\
\hline 5 & $\begin{array}{l}\text { Slow } \\
\text { internet }\end{array}$ & & & & \\
\hline
\end{tabular}

\begin{tabular}{|c|c|c|c|c|c|}
\hline & & & & $\checkmark$ & \\
\hline 6 & $\begin{array}{l}\text { Strange } \\
\text { Noise }\end{array}$ & & & & $\checkmark$ \\
\hline 7 & $\begin{array}{l}\text { Compute } \\
\mathrm{r} \text { is slow }\end{array}$ & & & 1 & \\
\hline 8 & $\begin{array}{l}\text { Failure } \\
\text { of } \\
\text { periphera } \\
\text { l device }\end{array}$ & & $\checkmark$ & & $\checkmark$ \\
\hline 9 & $\begin{array}{l}\text { Downloa } \\
\text { ds takes } \\
\text { forever }\end{array}$ & & & $\checkmark$ & \\
\hline 10 & $\begin{array}{l}\text { Compute } \\
\text { r freezes }\end{array}$ & & & & $\checkmark$ \\
\hline 11 & $\begin{array}{l}\text { App not } \\
\text { working }\end{array}$ & & & & $\checkmark$ \\
\hline \multirow{2}{*}{$\begin{array}{l}\text { SI } \\
\mathrm{N} \\
\mathrm{O}\end{array}$} & \multirow[b]{2}{*}{$\begin{array}{l}\text { Types of } \\
\text { the } \\
\text { failures }\end{array}$} & \multicolumn{4}{|c|}{ Advantages of using CPS } \\
\hline & & 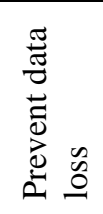 & 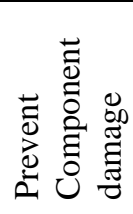 & 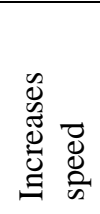 & 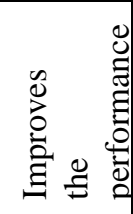 \\
\hline 12 & $\begin{array}{l}\text { Jumbled } \\
\text { computer } \\
\text { screen }\end{array}$ & & & & $\checkmark$ \\
\hline
\end{tabular}

\section{CONCLUSION}

CPS is defined as the combination of physics with cyber components potentially networked and tightly interconnected. The physic components may consist of process or system and the cyber components may consist of software or code. Finally the interfaces used in the CPS consist of network, analog to digital convertor (ADC) and digital to analog convertor (DAC). This paper shows a clear description of the function of CPS in various system failures. In future this system may also be useful in various fields. Some of the applications of this system aretracking and analysing of $\mathrm{CO} 2$ emission, detect traffic accidents, insurance telematics and provide situational awareness services to first responders, measure traffic, monitor cardiac patients, etc.

\section{REFERENCE}

1. https://en.wikipedia.org/wiki/Computer

2. https://en.wikipedia.org/wiki/Charles_Babbage

3. https://btob.co.nz/business-news/five-generations-computers

4. https://www.lifewire.com

5. https://www.thewindowsclub.co $\underline{\mathrm{m}}$ 
6. https://www.pcworld.com

7. https://www.computerhope.com

8. https://www.howtogeek.com

9. https://www.makeuseof.com

10. https://tech.co

11. https://study.com

12. https://www.icare-recovery.com

13. https://www.usatoday.com

14. https://github.com

15. https://smallbuisness.chron.com

16. cyberphysicalsystems.org

\section{AUTHORS PROFILE}

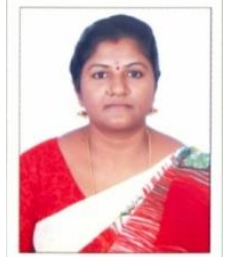

Dr.S.Hemalatha did her Bachelor degree in Computer Science and Engineering and Masters in Computer Science and Engineering University of Madras and Anna University Chennai, India in 2000, and 2004 respectively. She completed $\mathrm{PhD}$ in Computer Science and Engineering from Anna University, India in 2016. She has totally 17 years of experience in different engineering colleges and currently she is working as a Professor in Computer Science and Engineering in Panimalar Institute of Technology, Chennai, India. She has published 45 national and International journals and 30 papers in International conferences. She is the recipient of Distinguished Professor award from CSI Mumbai chapter in the year 2016, Professional achiever award from IEEE madras section in the year 2017. She has guided many UG and PG level projects and being a committee member and Research Scholars in Anna University. Her research areas are Network Security, Mobile Communication and Mobile Application Development. She is a member of CSI, IEEE and ISTE.

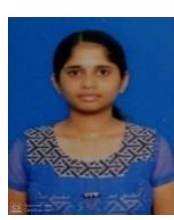

A.P.Shanthana Roja is a third year Computer Science and Engineering student in Panimalar Institute of Technology. She has demonstrated the Project Titled Effectively Optimized Examination remuneration using QR code in the IEEE Yesist12 International Project Competition. She is a member of Computer Society of India.

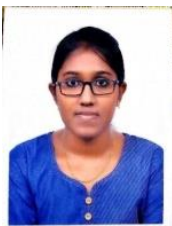

S. Suruthi is a third year Computer Science and Engineering student in Panimalar Institute of Technology. She has presented paper on proficient tagging of Sentiment Analysis in the Fourth International Conference on Innovation \& Emerging Trends in Engineering \& Technology. She is a member of Computer Society of India.

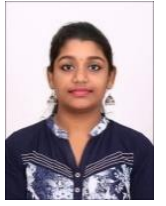

S. Srija is a third year Computer Science and Engineering student in Panimalar Institute of Technology. She has presented paper on proficient tagging of Sentiment Analysis in the Fourth International Conference on Innovation \& Emerging Trends in Engineering \& Technology. She is a member of Computer Society of India. 